\title{
Os sentidos de natureza na formação e na prática científica*
}

\author{
Eliane Brígida Morais Falcão \\ Flavio Silva Faria \\ Universidade Federal do Rio de Janeiro
}

\begin{abstract}
Resumo
lnvestigou-se o alcance das idéias, das imagens e dos conceitos associados ao termo natureza: de que modo cientistas - homens e mulheres que não apenas produzem ciência, mas formam outros cientistas - concebem a idéia de natureza? Exercício comparativo foi realizado com um grupo de sujeitos não acadêmico. Enunciados relacionados ao termo natureza foram investigados nos dois grupos: o primeiro era de pesquisadores-professores de um departamento de bioquímica, e o segundo de motoristas e trocadores de uma linha de ônibus. Mediante a metodologia de análise do discurso do sujeito coletivo, identificaram-se os discursos de natureza, de modo a permitir uma comparação entre eles. Foi usado o conceito de representação social. Mostrou-se que, entre os grupos, as diferenças de formação científica manifestaram-se nas exemplificações marcadas por termos técnicos, usadas pelos bioquímicos. No entanto, as categorias que fundamentam as idéias sobre natureza mostraram-se semelhantes. Foi possivel notar que os bioquímicos, mesmo lançando mão de natureza como referente do trabalho científico, acabaram por admitir, de modo geral, a sua incapacidade de precisar o significado do termo. Os resultados revelam a existência de uma lacuna na formação científica superior: a carência de uma formação epistemológica. Essa conclusão de cunho educacional é complementada por apontamentos sobre as relações entre formação científica, filosofia da ciência e impacto social da atividade científica.
\end{abstract}

\section{Palavras-chave}

Correspondência:

Eliane Brígida Morais Falcão

Rua Marechal Ramon Castilha, 265 apto.703

22290-175 - Rio de Janeiro - RJ

e-mail: elianebrigida@uol.com.br

Representação social de natureza - Bioquímicos - Motoristas de ônibus - Formação científica.

* Os autores agradecema Fernando Lefèvre, professor titular da Faculdade de Saúde Pública da USP, pela leitura crítica do original. 


\title{
The meanings of "nature" in scientific practice and formation
}

\author{
Eliane Brígida Morais Falcão \\ Flavio Silva Faria \\ Universidade Federal do Rio de Janeiro
}

Contact:

Eliane Brígida Morais Falcão

Rua Marechal Ramon Castilha, 265 apto.703

22290-175 - Rio de Janeiro - RJ

e-mail: elianebrigida@uol.com.br

\begin{abstract}
This is an investigation about the scope of the ideas, images and concepts associated to the word "nature": how do scientists men and women that not just make science but also train other scientists - conceive of nature? A comparative exercise was carried out with a group of non-academic subjects. Statements related to the phrase "nature" were investigated in two groups: the first was a group of teachers-researchers from a Biochemistry Department, and the second was composed of bus drivers and collectors. Using the methodology of "collective subject discourse analysis", the discourses about "nature" were identified, allowing the comparison between them. Use was made of the concept of social representation. It was shown that the differences in scientific formation between the groups were manifested in the technically laden examples given by the biochemists. Nevertheless, the categories giving support to the ideas about "nature" turned out to be similar across the groups. It was possible to notice that the biochemists, despite making use of "nature" as a referent for the scientific work, ended up admitting, by and large, their inability to give a precise meaning to the term. The results reveal the existence of a gap in higher scientific education: the lack of an epistemological formation. This conclusion, of an educational character, is complemented by notes on the relation between scientific formation, philosophy of science and the social impact of scientific activity.
\end{abstract}

\section{Keywords}

Social representation of nature - Biochemists - Bus drivers Scientific formation. 
Um dos problemas com os conceitos ou as noções de natureza é a falsa impressão de auto-evidência que costuma acompanhá-los em diversos tipos de discurso. De certo modo, isso ocorre com muitos outros conceitos, sendo exemplo disso as meticulosas distinções entre as diversas acepções do termo liberdade apresentadas nos dicionários de filosofia; outro exemplo é a diversidade de conceituações de gene em obras de ciências biológicas. Admite-se, entre estudiosos, que esse cuidadoso estabelecimento de distinções constitui um exercício intelectual necessário à separação segura entre o conhecimento rigoroso e as ambigüidades do senso comum.

Temos razões para crer que, no caso de natureza, esta muitas vezes almejada separação segura entre norma culta e senso comum é particularmente problemática. Nos últimos trezentos anos, apesar da extensão dos conhecimentos que obtivemos sobre natureza, tem-se a impressão de que o significado desse termo tornou-se progressivamente mais vago para os cientistas. É assim que, ao final dos anos 1950, um filósofo como Merleau-Ponty (2000) - para citar apenas um exemplo - podia escrever:

Sem dúvida, a posição do filósofo não é isenta de riscos. Como disse Bachelard, aquilo a que se chama 'natural' não passa, com freqüência, de má teoria. Mas se, como ele, se tem consciência da artificialidade do pensamento, não se necessita encontrar para este um contrário dialético, esse oponente sendo, senão a Natureza, pelo menos o percebido? 0 natural não deve ser um postulado preguiçoso [...]. Vamos tentar precisar essa idéia da Natureza pedindo ajuda às ciências. Mas de que modo o filósofo deve interrogar a ciência ? [...] A preocupação do filósofo é ver; a do cientista é encontrar pontos de apoio para explicar o fenômeno. 0 seu pensamento não é dirigido pela preocupação de ver, mas de intervir. Quer escapar ao atoleiro do ver filosófico. Por isso trabalha freqüentemente como um cego, por analogia. Conseguiu uma boa solução? Ele trata de experimentá-la numa outra coisa, porque teve êxito na primeira. 0 cientista tem a superstição dos meios que são bem sucedidos. Mas nessa tentativa para assegurar-se de um ponto de apoio, o cientista desvenda mais do que, de fato, vê. (p. 136-139)

Os resultados desse desvendamento são inestimáveis, pois o filósofo conclui: "Portanto, como não se interessar pela ciência para saber o que é a natureza?" Merleau-Ponty não pretende ser normativo: em nenhum momento, ele procura afirmar se os cientistas deveriam ou não modificar os seus pontos de vista. No entanto, podemos encontrar exemplos de cientistas naturais que, refletindo sobre o assunto, chegaram à conclusão de que esse é um ponto cego com efeitos danosos para a própria atividade científica. É o caso de C. H. Waddington (1979) que criticou duramente a visão de mundo espontânea dos cientistas naturais contemporâneos. Para ele, fazia sentido indagar até que ponto aqueles cientistas naturais compreenderiam ou teriam uma idéia clara sobre essa natureza a que o termo se refere.

Essa pergunta também emergiu para o nosso grupo de pesquisa durante uma investigação sobre representações do que é pensar cientificamente entre cientistas da natureza. Verificamos que os membros de um departamento de bioquímica britânico praticamente não recorreram ao termo natureza quando falaram sobre o seu objeto de estudo. Entre bioquímicos de um departamento brasileiro, pelo contrário, aquele termo foi freqüentemente usado para se referir ao objeto do pensamento científico (Falcão; Siqueira, 2003; Falcão, 2000). Pelo visto, a prática das ciências experimentais pode se desenvolver - e tem sido efetivamente desenvolvida - sem que, necessariamente, as pessoas nelas engajadas tenham um conceito consistente de natureza ou mesmo refiram-se explicitamente à natureza.

Os desenvolvimentos socioeconômicos globais nos últimos cinqüenta anos nos obrigam a repor esse problema em um contexto mais amplo. A expansão da sociedade industri- 
al, para alguns já pós-industrial, resultou no incessante afloramento de termos como natureza, ambiente natural ou riquezas naturais nos debates sociais e na linguagem do cotidiano. Nesse contexto, a natureza é vista como conjunto de condições e recursos do quais depende a vida em geral e, mais especificamente, a vida humana. A crescente importância dessas preocupações, aí incluído o impacto social da ciência, parece manifestar-se na superposição, quase na identificação, dos termos natureza e ambiente ou meio ambiente. Tal identificação se faz mais nítida quando os ecologistas fazem menções ao esgotamento ou à destruição daqueles recursos, tanto quanto à desfiguração ou descaracterização das paisagens. Se for assim, então a natureza, como conjunto de condições básicas de vida, estaria sendo agredida pelas próprias atividades das sociedades humanas atuais, fato que resultaria em uma ameaça à própria humanidade.

Seja qual for a extensão dessa ameaça, alguns autores preferiram descrevê-la como uma mutação decisiva na história humana, capaz de alterar os fundamentos da nossa existência. A referida mutação consistiria na construção de uma esfera artificial ao nosso redor que, a partir de agora, deveria ser vista como a condição básica da vida humana. É o que foi descrito por Bill MacKibben (1990) como "o fim da natureza”. Nesse caso, parte-se obviamente de uma definição de natureza plenamente identificada com a de ambiente ou meio ambiente. E como todos os antigos ecossistemas e territórios trazem, agora, a marca da técnica humana, não faria mais sentido falar em natureza, mas apenas em meio artificial humano.

Argumentações como a de MacKibben (1990) têm como pressuposto o crescente adensamento da relação entre ciência e economia: se podemos viver de uma tecnoeconomia é porque sabemos e podemos praticar uma tecnociência. Com isso, pretendemos nos referir principalmente - embora sem esgotar tudo o que pode ser denotado pelo termo tecnociência - a uma ciência natural que exige insumos de crescente complexidade tecnológica. Esses insumos, por sua vez, seriam inimagináveis sem prévias explorações científicas, estas também tecnologicamente complexas e assim por diante. Posta assim a questão, duas constatações se fazem necessárias. Em primeiro lugar, o vínculo entre ciência natural e tecnologia se insere em um ciclo produtivo bem definido, relacionado à já mencionada tecnoeconomia. Em segundo lugar, constatamos que vários sociólogos têm considerado o laboratório de ciência altamente tecnificado, como um sítio de práticas sociais que estariam nos obrigando a dissolver, na ordem do pensamento, qualquer conceito ou noção de natureza. Aqui, afirma-se que os objetos de estudo dos cientistas da natureza são cada vez mais construídos pelos próprios cientistas (Knorr-Cettina,1981; Barnes; Edge, 1982; Latour; Schwartz; Charvolin, 1998).

Estaríamos então assistindo a uma mudança do objeto de pesquisa dos cientistas? Uma resposta positiva a essa pergunta equivaleria a afirmar uma tese solidária e complementar àquela do fim da natureza. Poderíamos mesmo dizer que essa última tem um aroma ontológico ou até mesmo cosmológico (entendendo-se esse termo em sentido tradicional), enquanto a outra é a sua tradução em termos epistemológicos. Assim, no primeiro caso, admite-se que já existiu algo a que se refere 0 termo natureza, mas que doravante esse referente já não existe mais. Latour, Schwartz e Charvolin (1998), por sua vez, vêem naquele referente apenas um elemento convencional da cultura humana (ou de certa cultura), historicamente datado. E, pelo visto, condenado a desaparecer, como qualquer convenção humana.

Ambas as teses são, no mínimo, polêmicas. Isso porque elas partem de uma prévia restrição do significado do termo natureza, ainda que se reconheça nelas alguma capacidade de convencimento. A fonte dessa capacidade de convencimento parece residir na própria força dos temores e das esperanças que assombram o imaginário moderno, que se depara, quotidianamente, com os desfrutes e revezes 
oriundos da tecnologia e da sua economia racionalizada. 0 que Latour ou MacKibben parecem conseguir é simplesmente dar forma sistemática e racionalizada àqueles temores e esperanças. Registre-se, entretanto, que o imaginário coletivo que eles conseguem exprimir conceitualmente é restrito. Para muitos grupos humanos, as promessas de vida do ambiente artificial não passam de meras promessas. Por outro lado, os temores e as inseguranças a ele associados já são uma realidade global. No entanto, o ponto problemático nessas formulações está na transformação, por demais imediata, de categorias do (ou de certo) senso comum quotidiano em categorias teóricas ou críticas.

Explorando as abordagens de outros pensadores que se ocuparam desse tema, poderemos revelar alguns outros aspectos que consideramos relevantes. Nos momentos em que a reflexão dos cientistas e filósofos da era Moderna se dirigiu às determinações mais gerais do termo natureza, uma série de importantes temas foi destacada. É verdade que, de Descartes ou Leibniz até Einstein, passando por Lamarck, Darwin ou Kant, esses temas são considerados com distintas ênfases. Entretanto, as suas argumentações seguidamente giram em torno de categorias como tipos ou classes naturais de objetos, causalidade, explanação e, no que constitui um tema bastante debatido, as assim chamadas leis naturais. Se considerarmos esse continuado esforço teórico, poderemos ir além da dualidade natural/artificial como simples oposição entre objetos dados e objetos construídos.

Não será apresentada aqui uma revisão histórica do assunto, dada a complexidade de cada um desses temas, as suas relações dentro de cada sistema filosófico-científico e a própria diversidade desses sistemas. Apenas será suficiente indicar que, nos últimos trinta anos, filósofos como Rom Harré e Edward H. Madden (1975) e Roy Bhaskar (1977) argumentaram persuasivamente pelo estabelecimento de uma ontologia realista, caso se deseje tornar compreensível a atividade dos cientistas da natureza. Esse filão crítico ganha importância na me- dida em que se situa de modo diametralmente oposto àquele de autores como Latour ou MacKibben, delimitando um amplo espaço de possibilidades quanto a conceitos e idéias sobre natureza e natural.

Bhaskar (1977), em particular, criticou as filosofias da tradição empirista e a identificação entre sucessão regular de eventos (e também conjunção de eventos) e leis naturais. Contra isso, segundo ele, deve-se considerar que, na prática experimental da ciência, certos aspectos da realidade são isolados e submetidos a condições especiais. Somente sob essas condições podemos identificar determinadas regularidades, que nos dão acesso aos aspectos essenciais de estruturas reais e inteligíveis. Fora dessas circunstâncias, o mundo pode nos aparecer sem as regularidades e conjunções verificadas no laboratório, apesar da presença efetiva das acima mencionadas estruturas reais. 0 que aconteceria então, pergunta Bhaskar, se aderíssemos a uma teoria que apresenta a ciência simplesmente como uma descrição de sucessões ou conjunções regulares de eventos (univocamente correspondentes a experiências atomizadas)? Segundo ele, seríamos levados a admitir, uma de duas possibilidades: ou (a) que a ciência não é possivel, porque raras vezes o mundo dos eventos cotidianos mostra a regularidade de eventos que seria típica das leis naturais ou (b) que os próprios cientistas produzem as leis naturais, visto que no laboratório estas se manifestam como sucessões ou conjunções regulares de eventos. Diante dessas perspectivas, a alternativa apresentada pelo filósofo é o delineamento de uma ontologia realista, marcada por uma forte crítica das doutrinas deterministas, tendo em vista a distinção que estabelece entre os fenômenos e os mecanismos que os geram, perceptíveis ou não, sob a forma de regularidade de eventos na vida cotidiana. Ao mesmo tempo, é uma teoria da ciência que dá particular destaque ao esclarecimento da relação entre, por um lado, o caráter social e histórico da ciência natural moderna e, por outro, a sua capacidade de apreender as assim chamadas 
estruturas reais. A referência a estruturas reais, dotadas da propensão a certas atividades, serve então de fundamento a uma teoria da necessidade natural.

Nesse caso, o termo necessidade natural não exprime (a) uma pretensa relação necessária entre eventos, mas busca fundamentar em estruturas reais aquilo que percebemos no mundo eventos, sejam estes dotados ou não de fortes regularidades em suas ocorrências. Além disso (b), na medida em que a identificação dessas estruturas reais é vista como resultante do trabalho experimental/teórico (ou seja, elas são determináveis a posteriori), a necessidade natural diferencia-se da necessidade lógica (a priori), tais são os fundamentos do caráter não-determinista da ontologia proposta por Bhaskar (1977).

Esse tipo de debate não se desenrola sem conseqüências para o pensamento e a prática dos cientistas naturais. Na biologia, por exemplo, Brian Goodwin e Gerry Webster (1996) fizeram questão de destacar o fundo filosófico da divergência entre eles e o assim chamado campo neodarwiniano. Eles afirmaram que boa parte dessa divergência está relacionada ao problema da necessidade natural, no que tange às formas dos seres vivos. Nas ciências físicas, podemos identificar preocupações análogas, especialmente nas tentativas de afirmação não-ingênua do conceito de realidade. É o caso das obras de Mario Bunge (1974) e de llya Prigogine (1996).

Em todas essas considerações, o nosso objetivo é frisar que, para o pensamento ocidental, o termo natureza apresenta-se mais carregado de significados do que deixam transparecer as frases mais contundentes do movimento ecologista ou daqueles que se propõem a teorizálo. E que, além disso, a possibilidade de estudar a comunidade científica dos pontos de vista sociológico ou cultural não nos autoriza a reduzir o referente de termos como natureza a uma construção social, entendida no sentido restrito que exige exclusão da possibilidade de qualquer referente fora dos limites do discurso.
É com base nesses pressupostos que nos posicionamos como pesquisadores interessados na formação científica e na educação em ciências. Propomo-nos, neste artigo, ao apresentar os resultados de nossa pesquisa, a investigar o alcance das idéias, das imagens e dos conceitos associados ao termo natureza: de que modo os cientistas - homens e mulheres que não apenas produzem ciência, mas formam outros cientistas - concebem a idéia de natureza? Além disso, decidimos investigar essas mesmas representações em um grupo de indivíduos externo ao mundo acadêmico, cuja educação formal restringe-se, praticamente, ao Ensino Fundamental. Pensamos que uma pesquisa comparativa nos ajudaria a compreender não só o espectro de representações de natureza entre os cientistas, mas também nos indicariam os vínculos entre essas concepções e o fundo cultural geral da sociedade.

Representação, nessa pesquisa, enquadra-se na linha conceitual de representação social, segundo Moscovici (2001):

Representando-se uma coisa ou uma noção, não produzimos unicamente nossas próprias idéias e imagens: criamos e transmitimos um produto progressivamente elaborado em inúmeros lugares, segundo regras variadas. Dentro desses limites, o fenômeno pode ser denominado representação social. (p. 63)

Nesse sentido, entende-se como representação social um conhecimento produzido socialmente, fora dos parâmetros estritos do conhecimento científico, e que aguarda estreita vinculação com a situação social onde é desenvolvida.

\section{Metodologia}

A pesquisa foi realizada com dois grupos distintos, sendo o primeiro de classe média, com educação formal de nível acadêmico-científico. Tomamos como primeiro grupo os docentes de um departamento de bioquímica de uma universidade pública do Rio de Janeiro. De maneira 
geral, os compromissos profissionais desses sujeitos incluem o ensino universitário, a orientação de pós-graduandos e o desenvolvimento de linhas de pesquisa em área biomédica ou biológica. Como segundo grupo, tomamos um conjunto de profissionais cuja escolaridade restringe-se ao nível fundamental (ocasionalmente médio): motoristas de ônibus e trocadores de uma linha que liga a zona sul à zona norte do Rio de Janeiro.

A todos os sujeitos, foram apresentadas, individualmente e em seus locais de trabalho, as perguntas: 0 que é natureza? Caneta faz parte da natureza? A primeira teve a finalidade de estimular uma fala livre sobre as idéias em relação ao tema natureza. A segunda buscou provocar a reflexão mais explícita sobre a relação entre o natural e o artificial, uma vez que pesquisas anteriores mostraram aos pesquisadores que tal oposição se manifestava com freqüência de forma nem sempre explícita'.

A organização e análise das respostas dadas à pergunta, tema central da pesquisa, isto é, a identificação das representações sociais de natureza, obedeceu aos procedimentos de análise qualitativa denominada Análise do Discurso do Sujeito Coletivo - DSC (Lefèvre; Lefèvre; Teixeira, 2000; Lefèvre; Lefèvre, 2003).

Essa abordagem fundamenta-se na teoria da representação social e seus pressupostos sociológicos. Segundo essa abordagem, grupos sociais específicos compartilham idéias, crenças e valores comuns (ou padrões ideológicos), ou seja, dispõem de um imaginário social, comum, coletivo, existente num dado momento.

O DSC é uma metodologia que estabelece um caminho sistemático para identificação desses padrões, ou representações sociais, de grupos específicos em relação a determinados temas. Buscase, por meio dela, reconstituir,

[...] com partes de discursos individuais, como um quebra-cabeças, tantos discursossintese quantos se julgue necessário para expressar uma determinada figura ou tema. (Lefèvre; Lefèvre; Teixeira, 2000, p. 19)
0 procedimento metodológico básico exige que se identifiquem as idéias centrais e expressões-chave semelhantes presentes nos depoimentos dos respondentes e então compor, com as expressões-chave desses depoimentos semelhantes, um discurso-síntese para cada idéia central distinta, redigido na primeira pessoa do singular.

0 resultado final busca produzir no leitor a sensação de um discurso real de um falante concreto, com vistas a configurar um sujeito coletivo de um discurso que revela uma determinada opinião ou representação coletiva sobre um tema.

Esse sujeito coletivo, falando na primeira pessoa do singular, é um recurso metodológico desenvolvido pela técnica do DSC para revelar, concretamente, que quando os indivíduos pensam é também a sociedade que está pensando por meio deles. 0 conjunto dessas representações veiculadas pelos DSC seria uma forma de resgatar ou de se aproximar da estrutura simbólica a respeito de um dado tema, presente numa determinada formação social, num determinado tempo.

\section{Resultados}

Os resultados - DSC - relativos ao grupo acadêmico e não acadêmico estão apresentados no Quadro (no final do texto) de forma a permitir a leitura comparativa.

Conforme é possivel identificar, na leitura do Quadro, boa parte dos discursos (DSC) dos sujeitos acadêmicos desenvolve-se em torno de temas coincidentes com aqueles mencionados pelos sujeitos não acadêmicos. A diferença que sobressai entre os dois grupos é o uso mais freqüente, por parte do grupo acadêmico, de exemplos expressos em terminologia com maior conteúdo técnico. Isso ocorre no DSC 1 (referência à ovelha Dolly, no nível do organismo, proteína etc.); no DSC 3 (transformações

1. As pesquisas mencionadas também mostraram a vinculação de idéias religiosas às idéias sobre natureza e, por isso, optou-se por perguntar também a cada um dos sujeitos se acreditava em Deus e se tinha religião. 
bioquímicas, nomes e classes de moléculas orgânicas, desintegração do átomo etc.) e no DSC 6 (novamente Dolly, mais a sua descendência, proteína clonada etc.).

Contudo, essas referências a conceitos de ciência natural (presumivelmente bem compreendidos pelos autores das declarações) parecem funcionar como exemplos que se interligam numa trama representativa não muito diferente da que observamos no discurso dos sujeitos não acadêmicos: uma idéia da natureza como aquilo que de mais amplo ou compreensivo podemos conceber. Até mesmo as incertezas a respeito da caneta, dos objetos feitos pelo homem, parecem levar às mesmas contraposições, em ambos os grupos:

[...] a caneta não seria natureza, porque foi produzida pelo homem; também a ovelha Dolly que tanto não é que virou notícia [...]. DSC 1 - Acadêmicos - Natureza natural [...] materiais, caneta, carpete, mar, tudo faz parte da natureza [...] o completamente artificial não existe [...]. DSC 3 - Acadêmicos - Natureza inclusiva

Essa passagem de uma idéia a outra parece ser do mesmo tipo da que ocorre nas seguintes passagens do grupo não acadêmico:

Caneta não faz parte, porque não é viva e natural, é industrializada [...]. DSC 1 - Não acadêmicos - Natureza natural

A caneta não é natureza: é sem vida, foi feita pelo homem [...]. DSC 2 - Não acadêmicos - Natureza natural criada A caneta, também (não tenho tanta certeza) é um meio de transporte do que a gente sente [...]. DSC 4 - Não acadêmicos - Natureza inclusiva criada

Assim, vemos, nos discursos de ambos os grupos, a base comum de uma tradição cultural de concepção de natureza, que genericamente soma componentes naturais do mundo (intocados pelo homem) em contra- posição aos componentes artificiais (intervenções humanas).

\section{Discussão dos resultados}

Começamos por ressaltar, entre os dois grupos de sujeitos, a presença de um tema importante, ainda que menos explícito, evidenciando discrepâncias e concordâncias. Trata-se da associação de natureza e vida nos DSC natureza natural, natureza inclusiva e natureza criada. Numa primeira leitura, tal associação aparece como típica dos sujeitos não acadêmicos:

Tudo que tem vida, ou quase tudo [...]; A caneta não é natureza: é sem vida [...]. DSC 1 - Não acadêmicos - Natureza natural

Contudo, essa mesma passagem permite concluir que a associação entre o vivo e o nãovivo é sentida como insuficiente pelo próprio sujeito que a pronuncia. A expressão ou quase tudo [que é vivo] nitidamente não visa eliminar certos seres vivos do natural, mas sim incluir coisas ou fenômenos percebidos como não vivos: chuva, estrelas etc. Com efeito, não há indícios nesses discursos de que montanhas, água, sol sejam vivos, pelo menos não no sentido em que o são as aves, os humanos e as plantas.

Ao mesmo tempo, a análise dos discursos revelou nas respostas dos sujeitos-acadêmicos uma idéia aparentada, só que não explicitamente mencionada como vida. Vejamos:

Natureza está ligada ao anterior, à origem, é a origem, as coisas originais [...]. Pode-se entendê-la como um conjunto de várias coisas que existem e se perpetuam [...]. DSC 1 - Acadêmicos - Natureza natural

\section{Ou ainda:}

Natureza seria tudo, causa e destino de todo o universo. Seria análoga à idéia de Deus, no sentido filosófico. DSC 3 - Acadêmicos - Natureza inclusiva 
Tais idéias sugerem que, para os acadêmicos, vida talvez seja um termo muito forte ${ }^{2}$ para ser aplicado à natureza em geral, preferindo estes falar de causa, origem, perpetuar-se. No entanto, em que consiste essa origem ou esse perpetuar-se das coisas? Embora se perceba aqui certa indeterminação, tais termos ou expressões remetem a um dos sentidos mais antigos de natureza: o anterior, a origem, associado ao que existe e se perpetua, faz-nos lembrar da physis na filosofia clássica. As falas acima mencionadas acabam por incluir uma decidida divisão entre animados e inanimados, ambos como naturais, como é possível também notar em mais este exemplo:

É uma visão diferente da dos ecologistas: inclui inanimados como caneta, derivado do petróleo. DSC 3 - Acadêmicos - Natureza inclusiva

Somos assim levados à conclusão de que o uso do termo vida não implica em divergência significativa entre os discursos dos dois grupos.

Passamos agora a um outro tema que ocorre de modo diferenciado, segundo o grupo considerado. A natureza é seguidamente caracterizada como dádiva de Deus, como criação, segundo os sujeitos não acadêmicos. Já entre os acadêmicos, essa referência quase não se faz sentir. Ainda assim, é digno de nota que a natureza foi comparada, por analogia, "com a idéia de Deus, no sentido filosófico”. Essa referência a Deus exprime, de certo modo, uma apreensão da natureza como unidade, mesmo que tal unidade seja fugidia, como se depreende na seguinte passagem:

Somos todos e tudo do universo, o que é animado e inanimado, na medida em que tudo tem uma anima; não se consegue explicar, não se reduz a imagens que eu percebo das coisas, algo [que] não se capta inteiramente mas que existe [...]. DSC 3 Acadêmicos - Natureza inclusiva
Essa mesma busca de unidade é o que transparece na referência explícita a Deus que observamos no discurso não acadêmico sobre a natureza inclusiva. Nesse caso, a principal distinção entre os dois grupos parece ser o caráter de dádiva, que subjaz a essa unidade para os não-acadêmicos, em comparação com o conteúdo aparentemente mais secularizado daquela unidade, entre os acadêmicos. Dados da investigação mostram que crenças religiosas são importantes características do perfil cultural desse grupo acadêmico ${ }^{3}$, o que reforça o sentido de nossa interpretação.

Se voltarmos nossa atenção para a diversidade interna ao grupo acadêmico, poderemos encontrar elementos discursivos relevantes para o debate filosófico sobre o conceito de natureza. Os DSC 1 (Natureza natural) e DSC $3(\mathrm{Na}-$ tureza inclusiva) praticamente encerram todas as idéias desses sujeitos com relação à natureza como objetividade. Podemos encontrar aqui, sob forma particularizada, as teses dos autores em sociologia da ciência, mencionados na introdução deste artigo:

Como sou bióloga, vejo tudo no nível do organismo. Então proteína não faz parte da natureza, mas faz parte dos seres da natureza, não existe sozinha. DSC 1 - Acadêmicos - Natureza natural

A auto-identificada bióloga ainda reconhece o natural naquilo que é íntegro, primordial, mas já não identifica como natural a proteína por ela isolada do corpo de um organismo. No entanto, quem toma essa frase como princípio chegará à conclusão de que os nossos procedimentos, ao se voltarem cada vez mais para elementos

2. Por mais que existam diferentes definições de vida e de ser vivo, os cientistas naturais admitem que os processos referentes à vida são 0 objeto de estudo de um campo do saber bem determinado, denominado Biologia. A aplicação desse termo à natureza em geral seria então rejeitada pelo cientista moderno como uma forma de animismo.

3. Dados da pesquisa, aqui apresentada, indicam que o perfil cultural do grupo acadêmico inclui a presença de crenças religiosas. Pelo menos $60 \%$ do grupo crêem em Deus e 27\% declararam-se em dúvida. Quanto ao grupo não acadêmico, 100\% declararam crer em Deus (dados não publicados dos autores). 
isolados, irão abolir o caráter natural dos objetos de estudo dos cientistas. Pois bem, essa parece ser exatamente a dedução que se exprime na linha discursiva DSC 3 - Natureza inclusiva:

Acho que isso tem a ver com o nosso trabalho, partimos do ser vivo e chegamos à molécula-proteína-aminoácido [...]. Pensando bem, o completamente 'artificial' não existe [...].

Nesses discursos, somos tentados a ver mais do que um agregado de impressões, mas momentos articulados de um mesmo imaginário. Façamos um exercício, visando mostrar como é possível transitar entre esses dois momentos mediante uma dedução. Tomemos como ponto de partida a totalidade das coisas experimentadas e percebidas, distinguindo as que são primordiais daquelas que sofreram transformações impostas pelo homem (sua vontade e sua racionalidade). Em seguida, enfatizemos o quanto podemos isolar elementos parciais do que antes era natural, criando objetos de estudo que, justamente por essa condição de parcial ou isolado, já não são mais natureza. Por fim, somos levados a admitir que a continuidade dessa prática nos obrigaria a reconhecer o fim, se não efetivo, pelo menos conceitual da natureza. Assim, quem parte de uma definição de natureza como coisas primordiais intocadas em contraposição ao artificial (coisas modificadas, resultado de manipulações humanas), é tendencialmente levado à dissolução de um desses domínios (o do natural) pela expansão cada vez maior do outro domínio (o do artificial). Convém observar que o movimento de pensamento que sugerimos acima deve ser entendido como possível. 0 importante é notar que os dois pólos (natureza natural/natureza inclusiva) desse possível movimento de pensamento coexistem de modo simultâneo no imaginário dos sujeitos investigados.

Apesar da convergência entre os discursos dos dois grupos, conforme indicado por nossas análises, foi possível identificar uma importante diferença: apenas entre os acadêmi- cos foi expresso o discurso da Dúvida (DSC 6 - Acadêmicos). É certo que localizamos algo semelhante entre os sujeitos não acadêmicos, qual seja o discurso do "não sei" (DSC 7 - Não acadêmicos). Entretanto, esse discurso aparece como um ponto isolado, quase um resíduo deixado pelo desenrolar de representações discursivas do grupo. Não chega a ser uma dúvida: é uma simples afirmação de ignorância. 0 mesmo não se dá com o discurso da dúvida entre os acadêmicos. Podemos interpretá-lo como o emergir da consciência de uma possível contradição entre os discursos Natureza natural e Natureza inclusiva, induzido pela interrogação sobre o caráter natural ou não natural de determinados objetos, como a caneta e principalmente a ovelha Dolly.

A caneta, que pareceu aqui assumir um forte caráter simbólico, provocou a dúvida quanto ao estatuto da cultura: "Nunca pensei: será que a parte cultural é natureza, as pirâmides fazem parte da natureza?" No entanto, a ovelha Dolly é particularmente evocativa da dúvida, levando o discurso a uma oscilação entre diversas definições de natureza. Mesmo quando se afirma que Dolly não é natureza, porque resultante de manipulação humana, fica-se em dúvida quanto ao seu filhote: “[...] a Dolly não é, mas o filho seria...?" 0 nascimento de um filhote de Dolly (por reprodução sexual comum) seria visto como um processo independente, autônomo. Nesse caso, embora o discurso parta da constatação de que Dolly resulta de manipulação, ainda assim ela pode implicar na ocorrência do autônomo, daquilo que tem vida própria, ou seja, do natural. Aqui há um conflito entre, por um lado, o caráter autônomo do natural e, por outro lado, o caráter não natural daquilo que é construído pela manipulação humana. 0 resultado é a dúvida. 0 mesmo se dá quando inicialmente afirma-se que "Dolly é uma bela imitação da natureza [...]”, mas depois se é levado a admitir que ela é "[...] viva, animada, vida independente [...]". Por isso, o discurso da dúvida dos sujeitos acadêmicos não é um correspondente exato 
do discurso "não sei” dos sujeitos não acadêmicos. A dúvida dos acadêmicos não é mera afirmação de desconhecimento (o que acaba sendo, no entanto, admitido), destacando-se por sua loquacidade. Esse discurso é pontuado por interrogações, sugerindo que o desconhecimento em questão não é algo a ser desprezado, mas encerra um problema. Em resumo, é um discurso que mobiliza todos os recursos e as representações dos discursos anteriormente discutidos, para terminar em uma indagação que, por vezes, deixa transparecer uma angústia: "O sentido popular de natureza todos conhecem, mas seus limites são cada vez mais obscuros [...]".

Por fim, devemos examinar um DSC comum a ambos os grupos investigados, qual seja a da Natureza como valor. Começando pelos sujeitos não acadêmicos, vemos que esse discurso apresenta alguma semelhança com os DSC natureza natural e natureza inclusiva, só que consideradas como objetos de desfrute. A natureza é fonte daquilo que constitui uma vida boa, desejável: saúde, bem-estar material, serenidade. A natureza que se exprime nesse discurso aproxima-se bastante do ambiente ou meio ambiente do ideário político-social do movimento ecologista. Isso é particularmente claro na expressão de um lugar-comum típico da preocupação ecológica: “[...] das árvores sai o oxigênio [...]” (DSC 5 - Não acadêmicos). Dessa natureza-ambiente, dependem coisas essenciais para uma vida agradável, desejável: saúde, alimentação, bem-estar físico. Notemos que também a fruição estética é contemplada pelo discurso: mar, montanha, pássaros.

As preocupações e aspirações que se exprimem nesse discurso formam uma referência explícita a necessidades humanas. No entanto, vale a pena ressaltar, essas necessidades não correspondem à necessidade natural discutida por filósofos e cientistas que se debruçaram sobre problemas como o das leis da natureza ou da causalidade. Elas devem antes ser encaradas como correlatas de precisão ou carência ${ }^{4}$. É relevante notar, ainda, no grupo de sujeitos não acadêmicos, uma forma variante desse discurso, no qual a caneta se mostra como símbolo ou de aquisições culturais ou de atividade intelectual (ou ambos): "A caneta também é natureza: tem que ter inteligência [...]”.

Entre os sujeitos acadêmicos, o DSC 5 Natureza como valor - também se apresenta como próxima à idéia de natureza identificada a ambiente. Como observamos no caso de outros discursos desse mesmo grupo, o uso de termos técnicos ou de exemplos científicos é abundante. Entretanto, sob essa especificidade do vocabulário, encontraremos os mesmos temas que verificamos no grupo não acadêmico. Novamente encontramos o desfrute material e estético e novamente iremos encontrar a referência às necessidades (carências, precisões) humanas:

A referência da natureza é a necessidade de manutenção da vida. Mas o arbítrio é nosso do que é necessário para a vida e sua manutenção: se caneta é necessário, então é natureza. DSC 5 - Acadêmicos

Por outro lado, a esse arbítrio das necessidades, que é nosso, justapõem-se como negativos outros resultados da cultura material humana: plástico, clone, revólver. Essa justaposição também se mostra no discurso Natureza como valor do grupo não acadêmico, como a evidenciar o ponto de origem, no senso comum moderno, das preocupações subjacentes à tese do fim da natureza.

Com base nessa análise comparativa, podemos dizer que o principal resultado atingido por nossa pesquisa foi a demonstração de que os discursos dos sujeitos coletivos grupo acadêmico e grupo não acadêmico estruturamse de modo muito semelhante, apesar das diferenças de educação formal e profissional entre esses grupos. Como era de se esperar, o discurso acadêmico destaca-se pela profusão de

4. Nesse contexto, podemos fazer um paralelo com a distinção, em língua inglesa, entre as formas substantivas need (carência, precisão) e necessity (aquilo que não poderia ocorrer de outro modo). 
termos técnicos especializados, empregados com evidente conhecimento de causa. No entanto, isso não chegou a se constituir em dificuldade, conforme procuramos mostrar, para estabelecer os pontos de identidade entre os dois grupos. A referência a Deus, mais evidente entre os sujeitos não acadêmicos, também deve ser relativizada. Ela acaba por nos remeter, conforme analisado, aos mesmos elementos discursivos que, para os sujeitos acadêmicos, constituem a sua visão mais secularizada da natureza inclusiva e da natureza natural.

Não obstante todas as semelhanças acima apontadas, revelando um fundo cultural comum entre os dois grupos, devemos ressaltar agora a importante exceção constituída pelo discurso da dúvida, restrito aos sujeitos acadêmicos. A inquietação por eles demonstrada ("Nunca pensei, será...?; Isto tudo é muito complicado...") nos leva a crer que, para eles, não podemos evitar as teses do fim da natureza e da construção social da natureza. Ou seja, a natureza parece se dissolver à medida que aumentamos o poder de nossas técnicas de análise e de intervenção ("Você introduz uma coisa na célula, já modificou...”). Contudo, essa intervenção incide sobre algo - a natureza que parece escapar a qualquer definição.

Seria possível argumentar, com base em nossos próprios resultados anteriores, que essa manifestação de dúvida é historicamente transitória. Conforme já mencionamos, identificou uma forte distinção entre bioquímicos brasileiros e britânicos, no que diz respeito à natureza como referência de objeto de pesquisa. 0 ponto de vista dos britânicos foi tentativamente explicado pela simplicidade dos sistemas e, relacionado a isso, pela maior complexidade e sofisticação do aparato técnico empregado em seus laboratórios. Segundo essa explicação que segue de perto a teorização de Latour, Schwartz e Charvolin (1998); Barnes e Edge (1982) e Knorr-Cettina (1981) -, poderíamos esperar uma modificação dos cientistas brasileiros, se estes viessem a se instrumentalizar de modo semelhante. É essa situação transitória que parece ser expressa, no discurso da dúvida dos sujeitos acadêmicos aqui estudados, em enunciados do tipo: "Acho que o homem não controla ainda a natureza...".

Conquanto seja esse um caminho promissor para o entendimento da mentalidade dos cientistas naturais, devemos perguntar se o ponto de vista daquele grupo de bioquímicos britânicos é inevitável. Lembremos, em primeiro lugar, o lugar preeminente ocupado pelas questões ambientais e de carência de recursos nos discursos sobre o natural em nossa sociedade. Em segundo lugar, observemos que os teóricos recentes da idéia de natureza tiveram a sua atenção fortemente captada pela produção humana de coisas que, supostamente, são acréscimos significativos ao natural (no sentido de coisas que constituem o mundo e não dependem da produção humana). São exemplos disso a produção de elementos químicos inexistentes sem a intervenção humana (Dagognet, 2000) ou a construção de genes artificiais pela engenharia genética (Latour; Schwartz; Charvolin, 1998). Entretanto, normalmente essas produções acontecem no ambiente fechado do laboratório, sob aquelas condições restritivas destacadas por filósofos da ciência como Bhaskar (1977). Resta saber até que ponto essas produções científicas (a) dissolvem de vez a natureza, real ou conceitualmente e (b) marcam uma mutação definitiva em nossas vidas, com a substituição da biosfera por uma tecnosfera (esse termo foi usado por G. Canguilhem, num ensaio publicado em 1976).

Podemos encontrar posturas mais cautelosas em uma série de cientistas preocupados com problemas tais como fontes energéticas, demografia, disponibilidade de recursos não renováveis e modificações climáticas. 0 geólogo Walter Youngquist (1997), por exemplo, qualificou (ou desqualificou...) como simples fantasias toda uma gama de cenários futuros de crescimento infinito que dependem de considerar os recursos não renováveis como recursos infinitamente renováveis. Ele enfatizou o irrealismo dos que pretendem ver nos corpos celestes uma fonte inesgotável de cobre. Mais ao ponto ainda, esse 
pesquisador destacou que a possibilidade teórica e experimental de converter elementos químicos uns nos outros não pode ser tomada como uma possibilidade séria de obter quantidades de cobre significativas para qualquer tipo de empreendimento social. Quanto a isso, é bom notar que também a produção de elementos químicos artificiais não é uma cornucópia de possibilidades inauditas. Esses elementos instáveis são produzidos em pequena escala e de modo algum apresentam propriedades inesperadas: eles são aquilo que podemos produzir de acordo com o que é previsto pela teoria química.

Vemos então que as produções da tecnociência seguem trilhos bastante restritos quanto às suas possibilidades, tanto no que diz respeito a originar componentes artificiais, quanto em sua capacidade de moldar a tecnosfera. Posições semelhantes foram manifestadas por estudiosos de ecologia humana (Hornborg, 2003). Assim, enquanto alguns pesquisadores sublinham a produção e reprodução de corpos e objetos pelos técnicos e cientistas, os pesquisadores que acabamos de citar enfatizam as condições restritas dessa produção. Enquanto os primeiros teorizam sobre as conseqüências de uma extensão a perder de vista das intervenções humanas sobre o meio, os últimos destacam os limites a essa extensão. Podemos identificar nessas condições restritas e nesses limites a presença de algo que deveriamos chamar de natureza? Não estaríamos aqui diante de uma natureza que é, ao mesmo tempo, fonte de possibilidades e restrição objetiva? Qual a relação entre essa possibilidade de abordagem da natureza, segundo os cientistas citados, e a filosofia dos epistemólogos que se referem à necessidade natural? Se o reconhecimento daqueles limites (inclusive como exemplos da necessidade natural) se traduzissem em uma norma de prudência na atividade tecnocientífica (e tecnoeconômica), não estaríamos assim reconhecendo a necessidade de estabelecer um vínculo entre decisões econômicas/científicas/filosóficas?

Essas perguntas apontam para uma série de conteúdos que está ausente do discurso social coletivo do grupo acadêmico por nós estudado. 0 que há de notável nessa ausência é que ela diz respeito a temas intimamente relacionados à natureza como objeto do pensamento científico. Tanto é que podemos encontrar esses mesmos temas nos discursos de cientistas atuantes, devidamente citados ao longo do presente artigo. Devemos também destacar que essa lacuna não parece ser típica apenas de cientistas brasileiros, conforme mostram os nossos dados prévios referentes aos bioquímicos britânicos. Ao que tudo indica, a formação dos cientistas - bem como a sua prática cotidiana - passa ao largo daquelas perguntas. É aqui, e encaminhando para as conclusões deste trabalho, que devemos tocar o problema da Educação Superior em Ciências.

\section{Conclusões}

Uma das metas básicas de quem se interessa por problemas de formação científica é a de garantir que os formandos desenvolvam um pensamento dotado de precisão conceitual. Isso se dá, é claro, em estreita ligação com outras preocupações, como a da metodologia científica, desenvolvimento de pensamento crítico etc. Assim é que o foco da atenção recai - até certo ponto com justiça - sobre o conteúdo de termos como átomo, partícula, célula, ecossistema, cristal etc. Ao mesmo tempo, busca-se dar a devida atenção à prática experimental da qual dependeu o desenvolvimento e a fundamentação desses conceitos. Para atingir essa meta, vários recursos educacionais entram em jogo: a estrutura geral dos currículos, o modo como os conceitos são apresentados, as técnicas didáticas, o recurso a demonstrações práticas, o uso de novas tecnologias educacionais e assim por diante. Aqui está em jogo, para retomar as já citadas palavras de Merleau-Ponty (2000), a aquisição de competência para "encontrar pontos de apoio para explicar o fenômeno". Não nos resta dúvida de que essas metas são devidamente valorizadas atualmente no âmbito acadêmico, mas ao mesmo tempo, verificamos que elas não exigem maiores pre- 
ocupações com os temas que identificamos como lacunas no discurso dos cientistas que estudamos.

Diante desse quadro, podemos tomar atitudes diferentes. Podemos considerar, por exemplo, que uma formação mais rigorosa em epistemologia - ou com discussões mais explícitas sobre a história e o significado do conceito de natureza - não é um fator decisivo para o processo educacional e para as atividades científicas. Nesse caso, quaisquer problemas trazidos pela extrema especialização da atividade dos cientistas poderiam, e deveriam, ser compensados por contrapressões da sociedade em geral. A atitude oposta seria a de argumentar que uma reflexão insuficiente sobre as possibilidades e os limites da ciência poderia resultar em certo irrealismo perante as possibilidades da tecnociência ou, então, no risco de a atividade científica transformar-se em um agregado de "meios bem-sucedidos" (como disse Merleau-Ponty, 2000), refratários aos juízos de valor. Contra a indiferença da outra atitude, pode-se argumentar que os enunciados dos especialistas e peritos (o que inclui os cientis- tas especializados) cada vez mais se tornam importantes para a tomada de decisões em diversas esferas da sociedade. Nesse caso, seria desejável que o cientista tivesse um campo de visão mais amplo, provocado, deliberadamente, por reflexões específicas incorporadas ao cotidiano das diferentes práticas que resultam no conhecimento científico: procedimentos de bancada, seminários, congressos etc. Concluímos pela importância da inclusão de tal reflexão no âmbito das práticas do trabalho científico, considerando sobretudo o DSC "Tenho dúvidas", que foi expresso apenas pelo grupo acadêmico de nossa pesquisa. Esse discurso, ressaltamos, foi produzido no transcorrer das entrevistas, nas quais os cientistas investigados se viram confrontados, e mesmo perplexos, com suas dificuldades de produzir um pensamento sobre aspectos relevantes de suas atividades profissionais. Com os resultados aqui apresentados, julgamos poder contribuir tanto para a ampliação da discussão sobre a idéia de natureza quanto para pensar caminhos de renovação da formação de nossos cientistas.

\section{Referências bibliográficas}

BARNES, B.; EDGE, D. Science in context. London: The Open University Press, 1982.

BHASKAR, R. A realist theory of science. London: Verso, 1977.

BUNGE, M. Teoria e realidade. São Paulo: Perspectiva, 1974.

DAGOGNET, F. Considérations sur l'idée de nature. Paris: Librairie Philosophique J. Vrin, 2000, p. 128-130.

FALCÃO, E. B. M. Variety in concepts of scientific thinking within a single field of science. Ciência e Cultura, v. 52, n. 1, p. 21-26, 2000.

FALCÃO, E. B. M.; SIQUEIRA, A. H. Pensar cientificamente: representação de uma cultura. Interface - Comunic. Saúde, Educ., v. 7, n. 13, p. 91-108, 2003.

HARRÉ, R.; MADDEN, H. Causal powers: a theory of natural necessity. Totowa: Rowman \& Littlefield, 1975.

HORNBORG, A. Cornucopia or zero-sum game? The epistemology of sustainability. Journal of world-systems research, v. 9, n. 2, p. 205-215, 2003.

KNORR-CETTINA, K. The manufacture of knowledge. London: Pergamon Press, 1981. 
LATOUR, B.; SCHWARTZ, C.; CHARVOLIN, F. Crises dos meios ambientais: desafios às ciências humanas. In: ARAÚJO, H. R. (Org.). Tecnociência e cultura: ensaios sobre o tempo presente. São Paulo: Estação Liberdade, 1998, p. 91-124.

LEFÈVRE, F.; LEFÈVRE, A. M. C. 0 discurso do sujeito coletivo: um novo enfoque em pesquisa qualitativa (desdobramentos). Caxias do Sul: EDUSC, 2003.

LEFÈVRE, F.; LEFÈVRE, A. M. C.; TEIXEIRA, J. V. 0 discurso do sujeito coletivo: uma nova abordagem metodológica. Caxias do Sul: EDUSC, 2000.

MACKIBBEN, B. 0 fim da natureza. Rio de Janeiro: Nova Fronteira, 1990.

MERLEAU-PONTY, M. A natureza. São Paulo: Martins Fontes, 2000.

MOSCOVICI, S. Das representações coletivas às representações sociais: elementos para uma história. In: JODELET, D. (Org.). As representações sociais. Rio de Janeiro: Eduerj, 2001.

PRIGOGINE, I. 0 fim das certezas: tempo, caos e as leis da natureza. São Paulo: Editora UNESP, 1996.

WADDINGTON, C. H. Instrumental para o pensamento. Belo Horizonte: Itatiaia; São Paulo: Edusp, 1979.

WEBSTER, G.; GOODWIN, B. Form and transformation: generative and relational principles in biology. Cambridge; New York: Cambridge University Press, 1996.

YOUNGQUIST, M. Myths and realities of mineral resources. Portland: National Book Company, 1997.

Recebido em 29.01.06

Aprovado em 16.04.07

Eliane Brígida Morais Falcão, doutora em Ciências, na COPPE (UFRJ), e pós-doutora na Universidade de Cambridge (UK), é professora-associada da Universidade Federal do Rio de Janeiro (UFRJ), no Núcleo de Tecnologia Educacional para a Saúde (NUTES).

Flavio Silva Faria, doutor em Biofísica pelo Instituto de Biofísica da UFRJ, é professor-adjunto da Universidade Federal do Rio de Janeiro (UFRJ), no Instituto de Biologia (IB). E-mail: flavio@biologia.ufrj.br. 
Quadro: Discursos do sujaito coletino (DSC) - Natureza

\begin{tabular}{|c|c|c|}
\hline & Sujeltos académicos & Sujeitos náo acadêmicos \\
\hline $\begin{array}{l}\text { DSC 1: Natureza } \\
\text { natural }\end{array}$ & 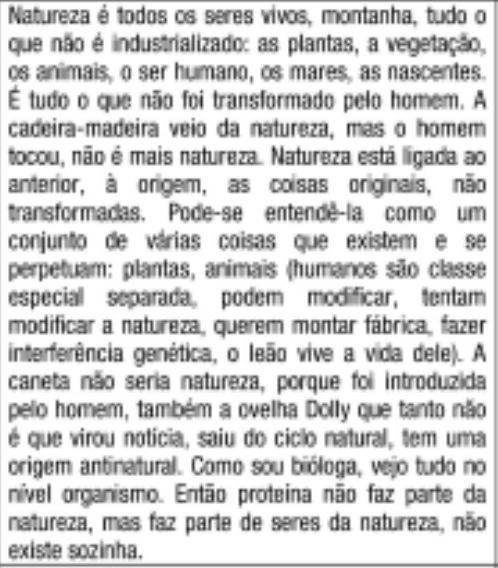 & 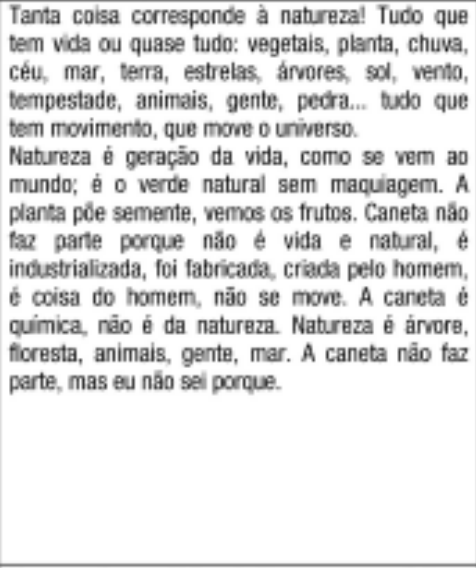 \\
\hline $\begin{array}{l}\text { DSC 2: natureza } \\
\text { natural criada por } \\
\text { Deus }\end{array}$ & Discurso nấ expresso & $\begin{array}{l}\text { Natureza é uma dádiva de Deus; natureza é Deus } \\
\text { e o que ele criou, todo o universo, tudo o que Ele } \\
\text { criou: árvore, animais, plantess, gente, mar, } \\
\text { montanha. Vendo a natureza já vejo Deus. A } \\
\text { natureza é à vida, o verde, as pessoas. A caneta } \\
\text { nảo é natureza: é sem vida, foi feita pelo homem. }\end{array}$ \\
\hline $\begin{array}{l}\text { DSC 3: natureza } \\
\text { inclusiva }\end{array}$ & 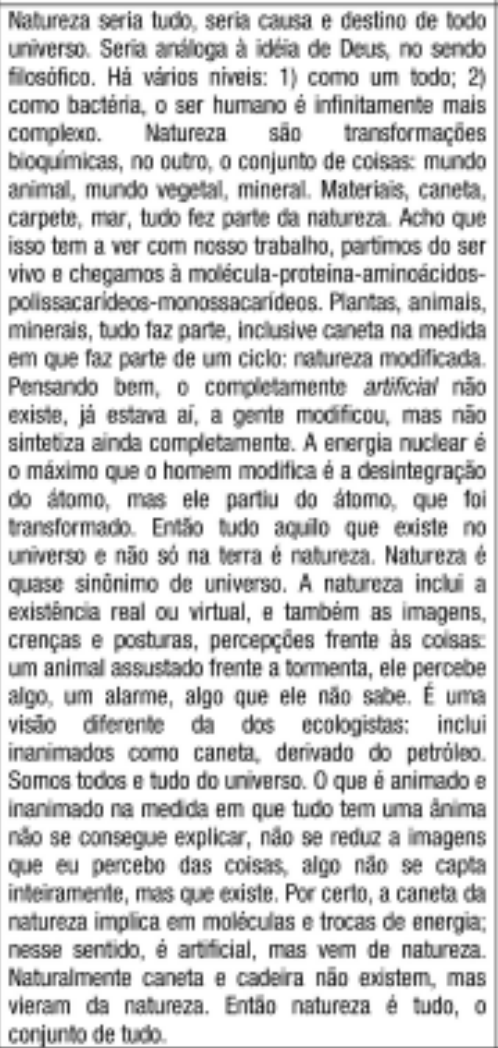 & Discurso กăo express \\
\hline $\begin{array}{l}\text { DSC 4: natureza } \\
\text { inclusiva criada } \\
\text { por Deus }\end{array}$ & Discurso nāo expresso & $\begin{array}{l}\text { Natureza é tudo que Deus deu: ar, sol, tudo: } \\
\text { onibus, tudo que está na terra é natureza: tudo ai, } \\
\text { céu, à, água, Deus, plantas, animais. A caneta, } \\
\text { tambèm (não tenho tanta certeza) é um meio de } \\
\text { transporte do que a gente sente }\end{array}$ \\
\hline
\end{tabular}




\begin{tabular}{|c|c|c|}
\hline $\begin{array}{l}\text { DSC 5: natureza } \\
\text { comb valer }\end{array}$ & 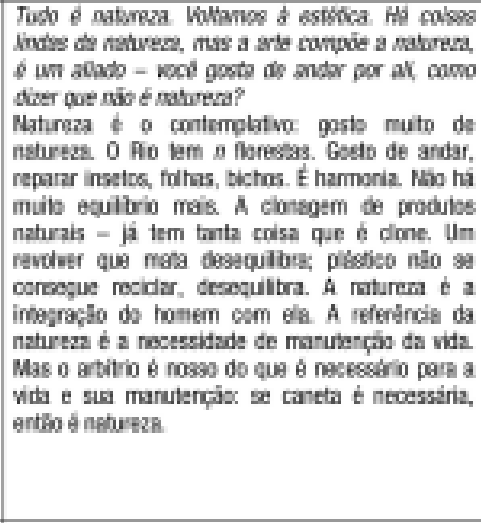 & 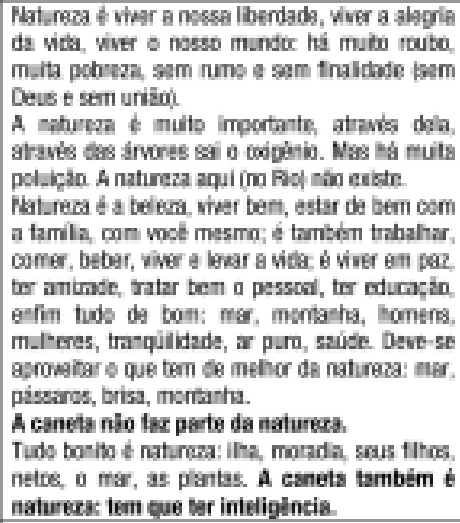 \\
\hline $\begin{array}{l}\text { DSC 6: Descurse } \\
\text { da dínida }\end{array}$ & 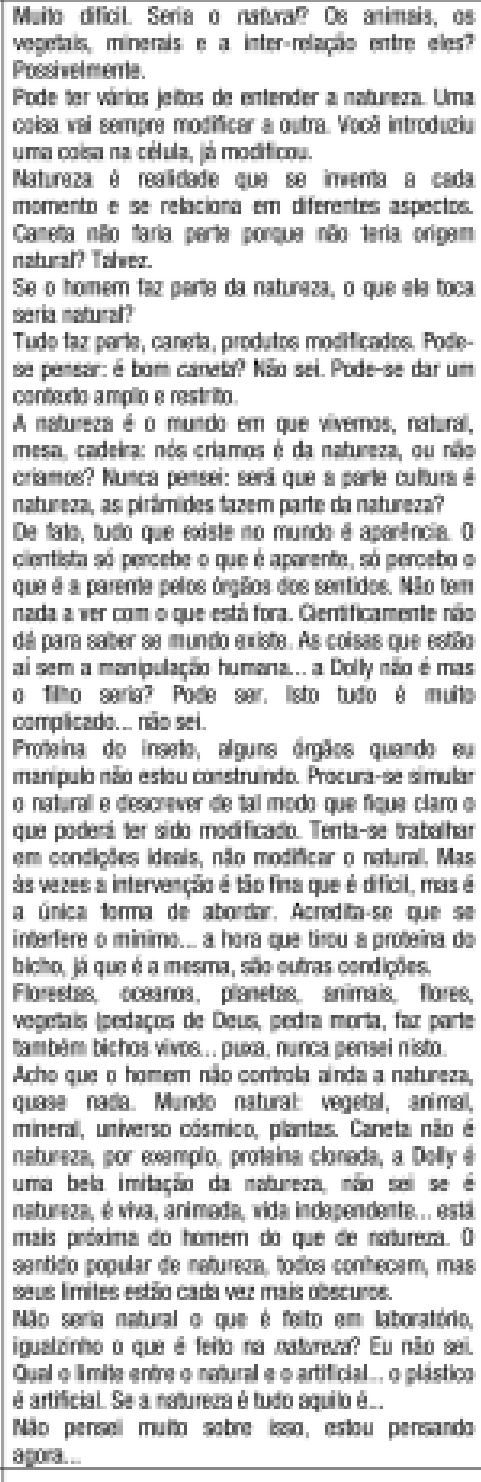 & Decurso nbo expresso \\
\hline DSC T: Kãb sai & & N5s sti \\
\hline
\end{tabular}

